\title{
Heuristic Approaches to SAXS: Fankuchen Award Lecture 2019
}

\author{
Eaton E. Lattman
}

Hauptman-Woodward Institute, 700 Ellicott Street, Buffalo, NY 14203. lattman3@gmail.com

Many of the previous recipients of this Award are intellectual heroes, and in some case valued mentors, of this year's recipient. The talk will present a few snapshots of their achievements, and will rehearse some of their connections to the awardee.

The body of the talk is inspired by the commitment to teaching recognized by the award. It will present a heuristic and relatively low-math approach to developing some of the essential concepts and equations of small angle x-ray scattering. It will also motivate interest in SAXS through a quick review of one or two new and genuinely exciting applications of the method. If time permits, heuristic approaches to crystallographic topics such as Bragg's Law will also be presented.

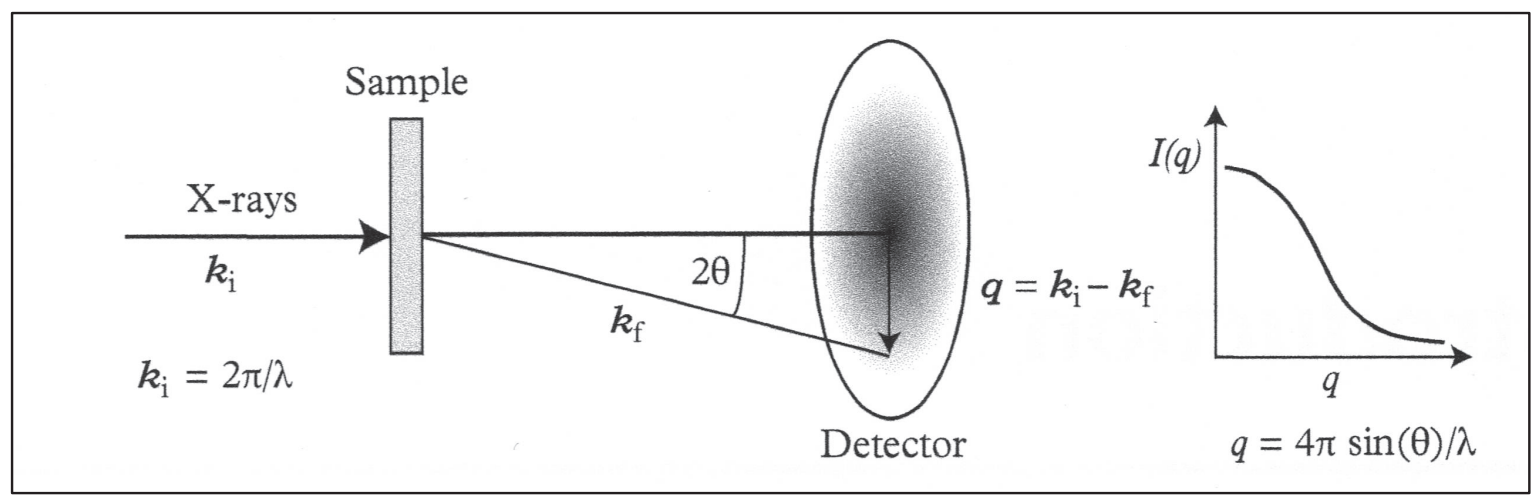

Figure 1. Schematic of the SAXS experiment; scattering from many molecules in random orientations combines to give a circularly symmetric diffraction pattern. A radial trace through this pattern, $I(q)$, represents the full experimental data. From Biological Small Angle Scattering by Lattman, Grant, and Snell. 